\title{
Fixed Cryogenic Vessel
}

National Cancer Institute

\section{Source}

National Cancer Institute. Fixed Cryogenic Vessel. NCI Thesaurus. Code C149517.

A static thermally insulated container designed to maintain the contents in the liquid state. 